\title{
A CIÊNCIA PÓS-DETERMINISTA, SUPRADISCIPLINAR E TRANSPARADIGMÁTICA: REACENDENDO O DEBATE SOBRE TEORIA, ANALOGIA E CONCEITO
}

\author{
Leo Peixoto Rodrigues ${ }^{1}$
}

\begin{abstract}
Resumo: Este artigo se inicia discutindo um tema relativamente clássico na epistemologia, qual seja, analogia, conceito e teoria, explorando uma perspectiva contemporânea do fazer científico e, em alguma medida, da filosofia. A partir daí, busca reacender o debate, sempre necessário, sobre teoria, analogia e conceito, à luz da produção do conhecimento científico, destacando abordagens supradisciplinares e transparadigmáticas. Para tanto, socorre-se de diferentes áreas do conhecimento científico, a sociologia clássica e contemporânea, elementos da biologia, aspectos da cibernética, para demostrar que a ciência, de modo geral, considerando suas múltiplas disciplinas, intercambia de forma cada vez mais dinâmica raciocínios analógicos, com vistas a dar conta da crescente complexidade em que se encontra.
\end{abstract}

Palavras-Chave: Ciências sociais. Ciências naturais. Teoria e conceito. Analogia e complexidade.

\section{À GUISA DE UMA INTRODUÇÁO: ANALOGIA, CONCEITO, TEORIA E CIÊNCIA}

As analogias têm cumprido um papel fundamental nas ciências sociais, de um modo geral, e na teoria sociológica, de um modo mais específico. Se for realizada, em profundidade, uma história das construçóes analógicas na produção de teorias científicas, de modo interdisciplinar, ao longo do desenvolvimento da ciência, constataremos que todas as disciplinas que a compóem, desde as mais antigas, como a física, até as mais jovens, como a própria sociologia, socorreram-se fartamente da utilização desse recurso cognitivo. Na ciência como um todo, é possível encontrar um "museu" teórico-epistemológico-analógico, cujas "peças", as analogias (algumas obsoletas, outras não), são muitas e de extrema curiosidade. Tais analogias

${ }^{1}$ Doutor em Sociologia pela UFRGS, Professor dos Programas de Pós-Graduação em Sociologia e em Ciência Política da Universidade Federal de Pelotas. https://orcid.org/0000-0003-3529-5016.

E-mail: leo.peixotto@gmail.com

http://dx.doi.org/10.1590/0101-3173.2020.v43n1.09.p151 
têm constituído as inúmeras teorias científicas ${ }^{2}$ que servem de modelo para descrever, representar e, por vezes, explicar o que chamamos de realidade (ou realidades) - matéria-prima de todo o fazer científico. Por vezes, explicitadas nas teorias, por vezes, implícitas, por vezes abandonadas após serem utilizadas para alguma "descoberta" científica, fato é que as analogias têm desempenhado um papel vital na inspiração e na construção de inúmeras arquiteturas teóricas.

Já na primeira metade do século XX, desde o seu início e mesmo um pouco antes, quando do descompasso entre filosofia e ciência, sobretudo quando a filosofia, no âmbito da teoria da ciência, não conseguia encontrar dimensôes fundacionais para os primeiros achados da física de partículas, ${ }^{3}$ foi possível assistir a uma série de questionamentos filosófico-epistemológicos, que não apenas retomaram o debate sobre as analogias como também contestavam a legitimidade do uso de analogias, de termos e de conceitos, oriundos, e transposto a áreas ou disciplinas diferentes. Enfatiza Rodrigues (2007, p. 17):

Um destes debates foi aquele travado com a publicaçâo do livro "Théorie Physique", [publicado em 1907] do físico e filósofo francês, Pierre Duhem. Segundo a epistemóloga Mary B. Hesse, o físico inglês N. R. Campbell, em seu livro "Physics, the Elements", publicado em 1920, "responde" às provocaçôes de Duhem. Hesse, em sua obra "Models and Analogies in Science", de 1966, buscou reconstruir os principais argumentos levantados tanto por Duhem como por Campbell em forma de diálogo.

O excerto acima citado refere-se a um histórico debate sobre a capacidade e a legitimidade de o conhecimento produzido, por meio de analogias, alçarse a um estatuto pleno de cientificidade, do ponto de vista epistemológico. Campbell (1920, p. 129) ${ }^{4}$ argumenta em favor do emprego de analogias, afirmando que elas são essenciais para a própria lógica da construçáo de teorias

$2 \mathrm{O}$ presente artigo nẫo pretende entrar nos meandros da tradiçấo filosófica quanto à capacidade heurística, de prova e/ou fundamentação das analogias, cujo debate continuou transcorrendo durante todo o século XX - com resultados relativamente pífios, salienta-se - e tendo sua origem concomitante à própria origem da filosofia moderna, principalmente nas diferentes tradiçóes do pensamento analítico. A proposta aqui é, de fato, voltar-se para a prática da ciência e o efetivo uso de analogias no conhecimento científico, no que se refere à construção de seus modelos explicativos (dos fenômenos), ou seja, as teorias.

${ }^{3}$ Embora a física sempre estivesse vinculada à filosofia natural desde os pré-socráticos, durante o século $\mathrm{XX}$, inúmeros filósofos dedicaram-se não apenas a compreender o comportamento da matéria em nível subatômico, mas também a revisitar diferentes pressupostos da tradiçấo filosófica. Dentre eles, poderíamos destacar: Gastão Bachelard (1977a, 1977b); neopositivistas, como, por exemplo, Karl Popper (1977, 1987); Mario Bunge (2000); Paul Feyerabend (2010), dentre tantos outros.

${ }^{4}$ Apud HESSE, 1966, p. 5. 
científicas. Cita o conhecido exemplo da teoria da dinâmica dos gases, a qual se ampara na analogia do movimento de bolas de bilhar. Diz que essa analogia foi essencial para a concepção teórica de como se comportam as moléculas de gás. Para Campbell, as analogias não apenas propiciam a predição de novas descobertas, como também fazem parte essencial das teorias que as sustentam; argumenta ele:

Todos aqueles que escreveram sobre os princípios da ciência falaram da relação estreita que une a analogia às teorias ou hipóteses. Pareceme, todavia que a maior parte deles interpretou falsamente a maneira como o problema se coloca. Apresentam as analogias como "auxiliares" a serviço da formação de hipóteses (termo pelo qual se acostumaram a designar o que eu prefiro chamar de teorias) e do progresso das ciências. No entanto, em meu parecer, as analogias não são simples auxiliares para o estabelecimento das teorias, mas sim parte integrante destas que, sem elas, estariam completamente desprovidas de valor e seriam indignas desse nome. (apud BOURDIEU; CHAMBOREDON; PASSERON, 1999, p. 234). ${ }^{5}$

A posição central de Campbell é a de que as analogias usadas para a produção de conhecimento científico, consideradas ou não como hipóteses, quando da "corroboração" desse conhecimento, devem ser vistas como fundamentação à investigação empírica. Para Campbell, a lógica da analogia é como a lógica da indução: pode ser descrita, mas não pode ser justificada.

Num interessante livro de Jean-Pierre Dupuy (1996, p. 27), ${ }^{6}$ que aborda as diversas analogias adotadas ao longo do desenvolvimento da cibernética, ${ }^{7}$ esse filósofo francês afirma que "conhecer é produzir um modelo do fenômeno e efetuar sobre ele manipulaçóes ordenadas. Todo o conhecimento é reprodução, representação, repetição, simulação." Ao contar a história da cibernética e revelar suas diversas analogias, Dupuy destaca a importância da utilização de analogias, homologia e modelos na construção do conhecimento

\footnotetext{
5 A citação acima, constante da obra de Campbell (1965), teve as páginas 123-128 integralmente transcritas no livro de Bourdieu, Chamboredon e Passeron (1999), o qual utilizamos.

${ }^{6}$ Trata-se da obra Aux origines des sciences cognitives, que aparece em língua francesa, em 1994, traduzida para o português, em 1996, edição que empregamos.

7 É relativamente comum encontrarmos aqueles que pensam que a cibernética é uma disciplina do conhecimento científico que desapareceu a partir da segunda metade do século XX. Não. Essa percepção é equivocada. A cibernética, desde as últimas duas décadas do século XX, passou a ser chamada de ciências cognitivas, de um modo geral, e, dada a sua fertilidade, ramificou-se em diferentes áreas, tais como informática, telemática, robótica, mecatrônica. Para um mais amplo conhecimento, ver: Wiener e Schadé, (1965), Ashby (1970), Dupuy (1996), Foerster (2003, 2006).
} 
científico. Para ele, a atividade essencial da ciência é a de construir "objetos" sob a forma de modelos representativos do "mundo": "o papel desempenhado pelas diversas formas de funcionalismo na ciência (inclusive nas ciências cognitivas) tem sua origem na prática universal da modelização." (DUPUY, 1996, p. 24, grifo do autor). Nas ciências humanas, mais especificamente na sociologia, a importância das analogias para a produção de conhecimento científico também é defendida por Bourdieu, Chamboredon e Passeron (1999, p. 67-68, 71, grifo nosso):

O raciocínio por analogia que é considerado por um grande número de epistemólogos como o primeiro princípio da invenção científica está voltado a desempenhar um papel específico na ciência sociológica que tem como especificidade não poder constituir seu objeto a não ser pelo procedimento comparativo [...] e para construir tais analogias pode, com toda a legitimidade, servir-se da hipótese de analogias de estrutura entre os fenômenos Sociais e fenômenos já formalizados por outras ciências, a começar pelas mais próximas - linguística, etnologia - ou até mesmo a Biologia. [...] A apreensäo das homologias estruturais nem sempre tem necessidade de recorrer ao formalismo para encontrar seus fundamentos e dar prova de seu rigor.

Não raramente, embora etimologicamente distintos, os termos analogia e homologia são utilizados como sinônimos, causando controvérsias ainda maiores sobre a legitimidade do uso de analogias para a produção do conhecimento científico. Se buscarmos as raízes gregas de tais vocábulos, verificaremos que ana (separação, dissolução) nos leva a conotar analogia como a possibilidade de transposiçâo do logos de um determinado domínio $x$ a um outro domínio, distinto, portanto $y$. Nesse caso, temos que semelhante raciocinio pode ser transposto de um domínio a outro. No caso das homologias, termo que geralmente vem acompanhado de um qualificativo (estrutural, funcional), significa que idêntico logos se encontra em dois ou mais domínios distintos, ou seja, a estrutura de um idem à estrutura de outro. Para alguns epistemólogos, o conhecimento analógico vai sempre depender de demonstrações - o que deverá ser formalizado de algum modo, no sentido teorético aristotélico -, ao passo que o das homologias, uma vez que seu rigor seja aceito em um determinado domínio, deve, também, ser aceito em qualquer outro homólogo.

As analogias inspiram, ajudam a pensar conceitos que constituem a estrutura teórica de toda e qualquer teoria científica. É o conjunto, a urdidura conceitual que dá corpo, vitalidade, capacidade explicativa às teorias. Nesse 
sentido, os conceitos, como dimensão intelectiva humana, carrega, levam consigo determinados conteúdos, unidades ou relaçóes de significação a linguística saussuriana chamou isso de signo: o som (significante) mais a imagem acústica (o significado) - que necessariamente está prenhe de conteúdo semântico. O uso de analogias na produção do conhecimento científico cumpre o papel de "daçâo" de significado ou ressignificação aos diferentes conceitos. As analogias significam e ressignificam os conceitos, inovando ou adaptando os já existentes a outras esferas de representação (teorização) do mundo.

As analogias constituem-se no amálgama que forma, que edifica, laboriosamente, as pontes cognitivas para que o conhecimento trafegue pelos domínios da subjetividade e da objetividade, por meio da elaboraçáo de conceitos, componentes edificantes das teorias. É nesse sentido que os conceitos, conforme nos mostram Deleuze e Guattari (1992), uma vez forjados por pensadores, não obstante as origens da sua criação, adquirem vida própria. Para eles, não existem conceitos simples, posto que todos são formados por componentes; compostos por "pedaços", partes de significados, de conteúdo semânticos que podem provir de "outros conceitos, que respondiam a outros problemas e supunham outros planos.” (1992, p. 29-30). É justamente por esse deslizar no tempo, mas se fazendo presença aqui e ali, nos conhecimentos que edificam, que, de acordo com Deleuze e Guattari (1992, p. 29), os conceitos não existem sem história, "[...] embora a história se desdobre em ziguezague, embora cruze outros problemas ou outros planos diferentes". Acrescentam os autores:

Com efeito, todo o conceito tendo um número finito de componentes, bifurcará sobre outros conceitos, compostos de outra maneira, mas que constituem outras regióes do mesmo plano, que correspondem a problemas conectáveis, participam de uma criação [...] O conceito é portanto, ao mesmo tempo absoluto e relativo: relativo a seus próprios componentes, aos outros conceitos, ao plano a partir do qual se delimita, aos problemas que se supóe deva resolver, mas absoluto pela condensação que opera, pelo lugar que ocupa sobre o plano, pelas condiçóes que impóe ao problema. (DELEUZE; GUATTARI, 1992, p. 30, 33-34).

Deleuze e Guattari (1992) nos fazem ver que os conceitos não são e nem devem ser vistos como prisioneiros das teorias, das disciplinas ou de qualquer área do conhecimento. São criaçóes cognitivas que portam inúmeros conteúdos (abstratos) que lhes foram derramados sobre, aqui e ali, e que 
por isso mesmo têm o poder livre da expressão - poder de associação, de desassociação, de ressemantização. Embora possam e devam ser vistos muitas vezes como cifrados, assinados e também compondo, por vezes, univocidade estreita entre aqueles que os percebem e os utilizam como veículo do dizível, do comunicável, a sua apreensão, a sua compreensão pode e deve ser capturada sempre relacionalmente, sempre hermeneuticamente, sempre em coadjuvância com o contexto teórico ou empírico: isto é, o que dá vida aos conceitos, às teorias, o que anima todo o tipo de conhecimento. As analogias, ao permitirem a circulação e ressemantização livre dos conceitos, cumprem esse papel construtivista do conhecimento.

Como os próprios filósofos Deleuze e Guattarri advertem, ao se referirem às características absolutas e relativas dos conceitos, é necessário o discernimento do "plano", da "regiāo" do "topos" nos quais tais conceitos estão operando, para que seja possível apossar-se da sua inextrincável relação de significação. Quando esse plano, essa matriz, esse contexto muda, pode ocorrer-lhes amoldamentos, readequaçóes, posto que a maleabilidade dos mesmos vai sempre reconstruir sentidos e estabelecer novos signos, fazendo-se insignia neste ou naquele novo topos específico. $\mathrm{O}$ conceito, oriundo ou não de analogias, na perspectiva deleuziana e guattariana, da qual compartilhamos, embora esteja a serviço da digressão, pois traz em si a permissão à divagação, à excursão, à abstração, paradoxalmente, está sempre se aproximando de novos sentidos, forjado a meio termo entre o relativo e o absoluto.

Uma concepção dinâmica de conhecimento científico ou filosófico, para fazer frente a uma realidade em que a representação clássica de si, já não mais consegue se sustentar, seja na filosofia, no que se refere aos grandes sistemas, aos metarrelados; seja na física clássica, com a suposta ordem harmônica e previsibilidade de seu movimento; seja na sociologia, com a "inexorável tendência" ao equilíbrio e coalescência, posto que um de suas mais provocantes interrogaçôes seja sobre como é possível a ordem social, tem exigido que a ciência, que as disciplinas que a compóem, que as teorias quanto às suas construçóes e aos seus conceitos, se ajustem a uma realidade em que o próprio conhecimento e o sucesso da modernidade como dimensóes ontológicas e ônticas fizeram emergir. A questão que se coloca, então, é como as teorias científicas, analogias e conceitos como construçôes cognitivas, cuja função é a de representar, modelar, aquilo que vivenciamos como "realidade" - seja essa realidade concreta, factual, virtual, abstrata, simbólica ou imagética - devam 
ser desenvolvidas e estabilizadas, em face de uma realidade vigorosamente cambiante.

\section{A GÊNESE DA SOCIOLOGIA E SEU INEXTRICÁVEL ENTRELAÇAMENTO ANALÓGiCO- CONCEITUAL}

Emile Durkheim foi indiscutivelmente um dos grandes teóricos do seu tempo. O fato de conseguir institucionalizar a sociologia como disciplina de cátedra, dando-lhe um objeto de pesquisa, um escopo teórico e um método de investigação, tornou-o, com justiça, um clássico. Clássicos são clássicos não pelo espaço de tempo decorrido entre ele e aqueles que deles falam, mas porque fincaram raízes profundas em algum lugar do conhecimento, constituindose como um marco, como referentes de onde partem ou aportam vozes que efetivamente se fazem ouvir. Durkheim é filho de um tempo e de um lugar específicos: a segunda metade do século XIX da Europa francesa. Isso por si só explica, em parte, as condiçóes de possibilidade da sua produção intelectual e da emergência da sociologia francesa.

Se considerarmos os "quatro mundos" 8 propostos pelo historiador Franklin L. Baumer, os quais caracterizam o século XIX "como estilos ou mundos de pensamento", constataremos que Durkheim nasce, em 1858, sob a égide do "terceiro mundo", o qual Baumer chama de "Mundo evolucionário", em que, "com Darwin, a questão da natureza torna-se, de novo, central não só para os cientistas, mas também para o público educado em geral [...] Assim, o período depois de 1859 tomou-se o apogeu do agnosticismo e da 'dúvida honesta'." (BAUMER, 1977, p. 19). Mas, se o "Mundo evolucionário” não entrou de imediato na França, como entrara na Inglaterra e na Alemanha, dada a resistência francesa ao darwinismo", a ponto de influenciar o jovem Durkheim com um evolucionismo quase "atávico", ele é confrontado com o

8 "Devido a esta multiplicidade sem precedentes, é preferível não considerar o século XIX como um todo, mas dispersá-lo num certo número de estilos ou mundos de pensamento. Com certeza que nenhum número tem qualquer significado particular, e pode fazer-se de vários modos este estudo do século. Mas com a estrutura desta obra no espírito, podem identificar-se quatro destes mundos que caracterizam este século. Podem chamar-se o Mundo Romântico, o Mundo do Neo-lluminismo, o Mundo Evolucionário, e o Fin-de-Siècle." (BAUMER, 1977, p. 16-17).

9 Segundo Baumer, "devemos notar que, em primeiro lugar, a evolução darwinista não era igualmente popular em todos os países. A França resistia mais do que a Inglaterra ou a Alemanha. Na França, a tradiçấo cuvierista e o positivismo reinante combinavam-se para tomar os cientistas desconfiados durante algum tempo em relação a qualquer espécie de teoria evolucionista. Darwin não foi eleito para a Académie des Sciences até 1878 , e mesmo nessa altura, por um voto menos do que conclusivo, e apenas como correspondente da secção botânica." (BAUMER, 1977, p. 16-17). 
conhecimento do chamado "Mundo Neo-Iluminismo", o segundo mundo do século XIX, na proposta de Baumer. O "Neo-Iluminismo" era avesso ao pensamento metafísico do Iluminismo do século XVIII ${ }^{10} \mathrm{e}$, nesse particular, foi a filosofia de Auguste Conte que não apenas datou a Modernidade, a partir do movimento industrial, mas também estabeleceu, em seu Curso de filosofia positiva", que aquele era o momento quando a maturidade do "espírito humano" se tornava plena e capaz de estabelecer as leis que regem a "física Social" (COMTE, 1983).

O cenário intelectual em que Durkheim emerge como pensador é aquele que, aproximadamente um quarto de século antes de seu nascimento, a filosofia positiva de Comte é formulada (1830-1842) e ganha especial atenção, na França. O positivo, em suma, propunha a aplicação dos métodos indutivo e dedutivo às ciências sociais, uma vez que, para Comte (1983, p. 8), "há dois séculos, pela ação combinada dos preceitos de Bacon, das concepçóes de Descartes e das descobertas de Galileu, momento em que o espírito da filosofia positiva começou", deveria tomar o acento e se opor ao espírito teológico e metafísico. Aproximadamente três décadas depois do nascimento de Durkheim, o evolucionismo darwinista e spenceriano ${ }^{11}$ tomava conta de boa parte do espírito europeu. Alfred Fouillée, filósofo francês, chegou a afirmar, em 1896: "A segunda metade do nosso século [o século XIX], é evolucionista. Um positivismo dinâmico substituiu o antigo positivismo estático." 12

A ciência, nesse contexto, estava em franca expansão, e a possibilidade de novas disciplinas, no bojo do conhecimento científico, não apenas era vislumbrada como possível, mas também necessária. Durkheim percebeu isso muito cedo. Na Alemanha, Wilhelm Wundt fundava a psicologia, como uma disciplina autônoma da filosofia; organizara um laboratório de psicologia experimental, em 1879, o qual Durkheim teve oportunidade de conhecer, em 1886, com aproximadamente trinta anos de idade, ficando particularmente impressionado. Em 1892, Durkheim publica $A$ divisáo do trabalho social,

\footnotetext{
${ }^{10} \mathrm{Na}$ visão de Baumer (1977), "Mundo Neo-Iluminismo" contrastava com o "Mundo Romântico" das primeiras décadas do século XIX e que, na verdade, pode ser considerado como o "primeiro grande protesto contra o "mundo moderno".

${ }^{11}$ Em 1862, Herbert Spencer publica sua obra Primeiros Princípios. Ela se constitui num verdadeiro tratado sobre filosofia da evolução. Discute diferentes aspectos do evolucionismo, ao tempo em que apresenta diferentes tipos de evolução, buscando abranger uma variada gama de processos evolutivos, tais como evolução da astronomia e meteorologia, evolução da geologia, evolução orgânica, evoluçáo funcional, evolução social, evolução da língua, evolução da humanidade, evolução universal, dentre outras (SPENCER, 2003)
}

${ }^{12} \mathrm{O}$ evolucionismo estático a que se referia era o de Comte (apud BAUMER, 1977, p. 97). 
sua tese de doutorado, um dos primeiros trabalhos de fôlego e que se torna conhecido, pela sua originalidade (DURKHEIM, 1978).

A criação de uma nova disciplina científica, naquele período de ascensão da ciência, exigia, com muito rigor, a proposição de um objeto, de método e de escopo teórico, todos bem definidos. Durkheim fez isso com maestria. $\mathrm{Na}$ sociologia, mesmo a de hoje, quando esse clássico francês é estudado, a ênfase dada costuma ser ao seu objeto de estudo, os fatos sociais, ao seu método, como sendo positivista-organicista-funcionalista. Entretanto, quando suas abordagens teóricas são estudadas, considerando-se o conjunto de seus conceitos, as analogias que foram trazidas da biologia não são adequadamente apresentadas. O estudo teórico de Durkheim muito pouco ressalta o quanto ele se serviu do pensamento analógico, para descrever a sociedade da sua época. Durkheim constrói, de fato, seu aporte teórico tomando de empréstimo variadas analogias oriundas também da fisiologia, da psicologia e inclusive da própria física. Sua concepção de sociedade, sobretudo quando se refere à sociedade moderna, é a de um organismo vivo, constituído de partes, como qualquer outro organismo de maior complexidade. A sociedade também consiste em estrutura, aparelho ou sistema, cujos múltiplos órgãos (as instituições) estabelecem uma cooperação entre si para a manutenção coalescente desse todo. Em $A$ divisão do trabalho social (1995), por exemplo, são abundantes as passagens que indicam essa concepção teórica de sociedade. O sociólogo francês afirma: "Somos levados, assim, a nos perguntar se a divisão do trabalho não desempenharia o mesmo papel [...] a função de integrar o corpo social, assegurar sua unidade." (DURKHEIM, 1995, p. 29). Acrescenta ainda, ao aludir à função do Direito, nas sociedades modernas:

Em definitivo, o direito tem na sociedade um papel análogo ao do sistema nervoso no organismo. De fato, este tem por tarefa regular as diferentes funçōes do corpo, de maneira a fazê-las concorrer harmonicamente; ele exprime, assim, naturalmente, o estado de concentração a que chegou o organismo, em consequência da divisão do trabalho fisiológico. Por isso, pode-se medir, nos diferentes níveis da escala animal, o grau dessa concentraçáo segundo o desenvolvimento do sistema nervoso. Isso quer dizer que se pode igualmente medir o grau de concentraçâo a que chegou uma sociedade, em consequência da divisão do trabalho social, segundo o desenvolvimento do direito cooperativo com sançóes restitutivas. (DURKHEIM, 1995, p. 105, grifos nossos). 
Herbert Spencer, embora mais de duas décadas mais jovem que Comte, em seus escritos, manteve, a partir de um ponto de vista epistemológico, o indivíduo restrito a sua "individualidade", ou seja, não o pensou numa perspectiva de "autonomia do social” ou como algo ou alguém que possibilitasse uma "unidade coletiva", como fizera Durkheim com as "representaçôes coletivas". O organicismo funcionalista de Spencer, cuja reflexão é mais filosófica que sociológica, bebeu diretamente em Auguste Comte, em Adams Smith e na atmosfera evolucionista inglesa. Isso faz de Durkheim também um spenceriano, mas que se colocava a meio termo entre um evolucionismo individual (dentro de uma perspectiva psicologista) e um evolucionismo como espécie (dentro de uma perspectiva darwinista). Tal aspecto pode ser observado, quando argumenta: "Não só, de maneira geral, a solidariedade mecânica liga os homens menos fortemente do que a solidariedade orgânica, como também, à medida que avançamos na evolução social, ela vai se afrouxando cada vez mais." (DURKHEIM, 1995, p. 133). Conforme Durkheim, à medida que a sociedade evolui, a consciência coletiva vai se sobrepondo à consciência individual, agindo esta última de forma mais ativa sobre o indivíduo.

No século XX, após Durkheim, as analogias continuaram a ser utilizadas e deduzidas de outras analogias. As noçóes de estrutura e de função, que, de fato, tiveram sua sistematizaçáo com Durkheim, na primeira metade do século XX, conseguiram lugar de destaque na teoria social, principalmente na sociologia e na antropologia, acendendo a um estatuto não apenas de método e de teoria, mas também como fundamentação epistemológica - explicava-se o objeto, fundamentando-o na função. $\mathrm{O}$ chamado funcionalismo tornou-se pilar para o conhecimento social, espalhando-se por diversas escolas. Também se associara a outros termos, diversificando-se em correntes e diferenciando-se em algumas vertentes, como o funcionalismo de Franz Boas, o funcionalismo de Bronislaw Malinowsky, o funcionalismo de Radcliffe-Brown, o funcionalismo de Talcott Parsons, o funcionalismo de Robert Merton, e tantos outros. O funcionalismo trouxe, subjacentemente, analogias e conceitos que refletiam conhecimentos oriundos do fisiológico, do orgânico, do psicológico, do demográfico, das instituiçóes, da religiāo, os quais expressavam quase sempre relaçôes de teleologia, de finalidades em termos de usos, de busca de fins últimos (fundamento), como forma de explicação epistemológica.

Náo obstante todo o debate quanto à possibilidade de a ciência tratar verdadeiramente dos fenômenos travados, tanto no âmbito das 
ciências naturais como das ciências sociais, principalmente a partir de perspectivas filosófico-epistemológicas analíticas, as analogias - como formas cognitivas de transposição não apenas de logos, mas de conteúdo conceitual e de ressemantizaçôes entre diferentes domínios do conhecimento - não se constituíram em parte acessória da edificação da sociologia clássica francesa, como vimos, mas na própria fundamentação epistemológica e ontológica.

Se a seçâo dois deste artigo teve como objetivo apresentar as analogias, resgatando-as para o debate contemporâneo à luz da dos avanços da ciência de hoje, a seção que se segue tem por finalidade reconstruir, exemplificativamente, certos aspectos, momentos do próprio desenvolvimento científico em que o emprego de analogias sistêmicas foi fundamental, não apenas na construção de diversos avanços nas ciências naturais do século XX, como influenciou borrando definitivamente as fronteiras entre ciências naturais e sociais - o próprio desenvolvimento da sociologia, em diferentes momentos da sua teorização, no decorrer do século XX, com os aportes teóricos de Vilfredo Pareto (1917), Talcott Parson (1951) e Niklas Luhmann (1984). ${ }^{13}$

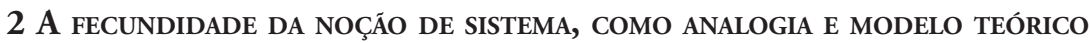 SUPRADISCIPLINAR}

Foi no âmbito das investigações cibernéticas que, ao simularem uma rede neural, Warren McCulloch e Walter Pitts, neurocientista e matemático, respectivamente, num conhecido artigo de 1943 - se não o precursor da cibernética, um dos que mais impulsionou o seu desenvolvimento ${ }^{14}$-, constataram que qualquer processo fisiológico podia ser expresso em regras lógicas e entendido em termos de redes. Redes, embora possam se expandir em diferentes "direções”, apresentam como característica intrínseca a constituição de alguns laços que se fecham entre/sobre si mesmos, retroalimentando-se. A noção de rede, como concebida na cibernética, traz necessariamente a noção de laços de realimentação e, consequentemente, a possibilidade de construção de uma unidade sistêmica.

\footnotetext{
${ }^{13}$ Anos em que suas obras teóricas, amparadas em analogias e modelos sistêmicos, foram desenvolvidas e publicadas pela primeira vez. Rodrigues (2013) resgata e conta, de forma mais pormenorizada, essa rica história sociológica e filosófica da ciência.

14 "A Logical Calculus of the Ideas Immanent in Nervous Activity", publicado em 1943, por Warren McCulloch e Walter Pitts, neurocientista e matemático, respectivamente.
} 
Na década de 1950, diversos experimentos foram desenvolvidos para a observação da emergência espontânea de ordem, em diferentes sistemas. A ideia de sistema, nesse âmbito de estudo, é justamente quando uma rede forma algum "laço de interação consigo mesma", 15 "fechando-se" como unidade de sentido (uma entidade) - fossem eles físicos, químicos ou biológicos e, mais tarde, também aqueles de natureza sociológica. Esses experimentos demonstravam que, independentemente do sistema observado e da aleatoriedade do seu ponto de partida, após certo tempo, eles revelavam um determinado "padráo" no seu operar. Tais padróes podiam se transformar, evoluir em diferentes direçôes comportamentais, mas sempre deixando um rastro "lógico", à observação, na forma como se comportavam (PRIGOGINE, 1996; CAPRA, 1997).

Ross Ashby (1970), em 1962, publica "Principles of the self-organizing system" um dos primeiros trabalhos que descreve o sistema nervoso como um sistema auto-organizado. Por seu turno, o físico e ciberneticista Heinz von Foerster teve um papel fundamental no desenvolvimento das pesquisas em auto-organização. Conforme Capra (1997, p. 79), ele manteve, durante duas décadas, desde os anos 1950, "um grupo de pesquisa interdisciplinar dedicado ao estudo de sistemas auto-organizadores, centralizado no 'Biological Computer Laboratory' da Universidade de Illinois."

Embora os trabalhos que se seguiram desde então, sobre a teoria de auto-organização, sejam fartos, ${ }^{16}$ poucos foram traduzidos, quer para português, quer para o espanhol, fazendo com que esse debate ficasse um tanto restrito aos países de língua anglo-saxã. Além disso, o fato de a teoria de auto-organização ser essencialmente transdisciplinar e usar linguagem marcadamente da física, da química e da biologia - disciplinas que lhe deram origem -, cuja sustentação teorética, muitas vezes, está expressa matematicamente, fez com que sua apropriação, sobretudo na América do Sul, ${ }^{17}$ fosse dificultada no âmbito das ciências sociais. Muitos outros pesquisadores, de diferentes partes do mundo,

${ }^{15}$ Conforme Epstein (1973, p. 23), "a retroação é a volta do efeito (saída) sobre a causa (entrada). Essa volta da informação obedece, em realidade, a certas constriçóes ou funçôes determinadas pelos reguladores." Para Foerster (2006, p. 23), a autorreferência é uma "operaçấo lógica pela qual uma operação toma a si mesma como objeto [...]"

${ }^{16}$ Uma das principais obras, contendo 58 artigos envolvendo a cibernética, com diferentes abordagens da teoria dos sistemas e distintos enfoques da teoria de auto-organização, escritos pelos principais pensadores da área, foi organizada por Walter Buckley, intitulada Modern Systems Research for the Behavioral Scientist e publicada em 1968, se constitui em um Sourcebook. Estamos utilizando a segunda edição, de 1969. Em espanhol, ver: Las Semillas de la Cibernética, um conjunto de obras escolhidas de Heinz von Foerster (2006). Ver ainda FOERSTER (2003) e WIENER; SCHADÉ (1965).

${ }^{17}$ Certamente o Chile, onde se desenvolveu a teoria de autopoiésis, é uma das únicas exceçōes. 
têm se interessado há mais de meio século pelo fenômeno da auto-organização, em diferentes áreas: Hermann Haken e Manfredo Eigen, na Alemanha; James Lovelock, na Inglaterra; Lynn Margulis, nos Estados Unidos; Humberto Maturana e Francisco Varela, no Chile; na sociologia, pode-se considerar Vilfredo Pareto, Talcott Parsons e Niklas Luhmann, aqueles que captaram a universalidade do conceito de sistema e suas mudanças, ao longo do século XX.

Foge ao objetivo deste artigo discutir, pormenorizadamente, a teoria de auto-organização e suas diferentes ramificaçôes. A história do desenvolvimento dessa abordagem teórica, certamente requereria algumas centenas de páginas, e uma pesquisa de largo fôlego. Herman Haken chegou a propor o desenvolvimento de um "campo interdisciplinar", denominado "sinergética", para o estudo dos fenômenos auto-organizativos, observados em diferentes disciplinas. ${ }^{18} \mathrm{Em}$ linhas gerais, as diferentes teorias de autoorganização apresentam as seguintes características:

a. pesquisam fenômenos em escala subatômica (ou quântica), atômica, molecular, microscópicas, macroscópica e cosmológica, isto é, do infinitamente micro ao infinitamente macro;

b. examinam fenômenos inorgânicos (compostos moleculares), orgânicos (a vida); materiais (concretos) imateriais (abstratos), como a informaçáo, o pensamento etc.;

c. buscam compreender e explicar como se dá a emergência daquilo que nós, humanos, observamos e entendemos como ordem, como organização, como inteligibilidade e como sentido;

d. utilizam-se da noção de sistema para se referirem às "unidades" de ordem que emergem em diferentes domínios e que permanecem produzindo - bifurcando-se, como menciona Prigogine (1996, p 72-74) - mais ordem, a partir de suas próprias estruturas, num processo contínuo de autodiferenciação, autorreferência e autocoevolução;

e. tais sistemas comportam-se como complexos, isto é, apresentam o que tem sido chamado de "dinâmica não linear" e que tem dado origem a teorias (também matemáticas) como a "teoria dos sistemas

\footnotetext{
${ }^{18}$ Ver Capra (1997, p. 84). Para um maior conhecimento de algumas das ideias de Haken, ver também conferência no Youtube: https://www.youtube.com/watch?v=UoMDvNIV3WU, e a Conferência "Synergetics: An interdisciplinary approach to Self-organization in complex systems". Disponível em: http://www.cee.usb.ve/CS-DC/Conference-Haken.pdf. Acesso em: 12 dez. 2016.
} 
dinâmicos", desenvolvida nas últimas décadas, para compreensão de múltiplos processos sistêmicos auto-organizativos.

A noção de auto-organização só se fez possível com a universalização da noção de sistema como expressão permanente e sinônima do termo ordem. Toda a organização, a qual apresenta uma dimensão dinâmica em seu operar, requer necessariamente a concepção de sistema, como forma de descrevê-la. Sistema tem sido, assim, o conceito que melhor descreve o comportamento de algo (vivente ou inerte, material ou imaterial) que se organiza e que toma como ponto de partida a si mesmo enquanto unidade de sentido. Dito de outro modo, sempre que ocorre o desencadear de ordem, de um determinado padrão ou, nos termos do que propóe Prigogine (1996), de uma "entropia reversa" ou "bifurcação", a melhor forma de descrever esse fenômeno é pela noção de sistema. Prigogine demonstrou, matematicamente, a formação de "conglomerados" de ordem que, escapando da entropia - dissipação de todo o sistema, isto é desordem -, "bifurcavam-se", fazendo emergir aquilo que se passou a identificar como ordem, padrão ou sistema. Esse fenômeno foi chamado por Prigogine de "sistemas afastados do equilíbrio". Ele também identificou, empiricamente, diferentes classes de sistemas desse tipo, as quais, além dos sistemas químicos auto-organizáveis (descoberta que lhe rendeu o Nobel de Química, em 1977), apontaram a vida e a sociedade como sistemas que apresentam esse mesmo comportamento (RODRIGUES; NEVES, 2017a, 2017b).

Aquilo que apontamos como sistema, em verdade, constitui-se em unidades ordenadas. Portanto, sistema é ordem - ordem em estado dinâmico, que, nos termos de Prigogine, se coloca afastada do equilíbrio. Assim, algo que se ordena dinamicamente, como a sociedade, por exemplo, torna-se quase impossível de ser descrito sem que recorramos ao uso dessa analogia universalizante: o sistema. A noção, o conceito de sistema coincide com a noção e o conceito de ordem, de unidade e de diferença. A ciência perderia boa parte da sua capacidade de representar/descrever o "mundo", seja de maneira empírica, seja teórica, sem recorrer à noção de sistema. ${ }^{19}$ É por isso que sistema consiste em uma espécie de universalização analógica, posto que, onde quer que haja ordem dinâmica, a sua forma de entendimento e de descrição não consegue

\footnotetext{
${ }^{19}$ Para uma discussão da utilizaçấo dos termos estrutura e sistema, ao longo do desenvolvimento teórico da sociologia, disputando espaço por "hegemonia conceitual" no campo da teoria, ver Rodrigues (2006, 2010).
} 
escapar da noção de sistema. A noção de sistema, portanto, não pertence a essa ou àquela disciplina (ou área) do conhecimento científico, mas à forma como se trata de tudo aquilo que apresenta alguma ordenaçâo dinâmica.

Para os teóricos da auto-organização, a "realidade", incluindo a realidade social, náo pode ser entendida como produzida, desenvolvida a partir de fora. Essa perspectiva - algo que é produzido sempre a partir de algo que vem de fora (causa sui) - é tributária de uma concepção epistemológica realista, linear, e não tem conseguido manter-se frente aos diversos avanços transdisciplinares da ciência, não obstante as controvérsias filosófica ou epistemológica. Aquilo que chamamos de realidade, ela mesma, só é realidade porque cria e recria a si própria o tempo todo, possibilitando a emergência de si mesma, através de permanentes esquemas nos quais se operam distinçôes, sobre distinçôes (observaçóes), segundo a teoria de auto-organização. É nesse mesmo sentido que Luhmann $(1998,2007)$ propóe que o sistema social seja compreendido e explicado em função de argumentos teóricos da auto-organização; também defende - em face de alguns críticos "cépticos" da interdisciplinaridade que, ao adotar o conceito de sistema, para descrever a sociedade, ele não está "simplesmente" propondo explicaçóes analógicas.

\section{SISTEMAS NATURAIS E SISTEMAS SOCIAIS, NUMA MESMA ORDEM: O QUE É HARD E O QUE É SOFT?}

Na década de 1970, dois biólogos chilenos, Humberto Maturana e Francisco Varela, revolucionaram o conhecimento biológico (e não somente), através da proposição do inovador conceito de autopoiésis, o qual se tornou mundialmente conhecido e utilizado no âmbito transdisciplinar. Esse conceito, numa primeira aproximação, teve por objetivo assumir uma renovada explicação sobre o que vem a ser um ser vivo, a vida. Entretanto, a noção de autopoiésis, dada a sua extrema originalidade, decorrente da capacidade desses biólogos em olhar a realidade do "vivente" por um viés absolutamente inaudito, desencadeou novas reflexóes sobre como a matéria viva se comporta. Além disso, ajudou a reposicionar o debate teórico sobre o conhecimento, exigindo novas posturas epistemológicas no que concerne à relaçáo entre observador/observado, conhecedor/conhecido e, corolariamente, questóes tais como "principialidade", emergência, finalidade, relação causal, interesse etc.

Entretanto, o conceito de autopoiésis, ao mesmo tempo em que se alicerçou na teoria de auto-organização, potencializou-a, trazendo-lhe avanços. 
Com a noção de auto-organização, Maturana e Varela (1980, p. xvii) vão estendêla e aprofundá-la para a compreensão dos seres vivos (vistos como sistemas), chegando ao conceito de autopoiési $5^{20}$ que descreve a "autonomia de um organismo vivo ao percebê-lo como um sistema que se autoproduz." Maturana (1980, p. $12)^{21}$ salienta que, "a partir de 1960, orientei minhas reflexóes para encontrar uma maneira de falar dos seres vivos que captasse a constituição de sua autonomia como sistemas [...] tanto em sua dinâmica relacional como em sua dinâmica interna." Maturana e Varela partem da percepçáo de que tal sistema, o vivo, tem sua dinâmica voltada a si própria, referindo-se (e se autorreferenciando) com relação a seus próprios componentes (autorreferência), para se autoproduzirem como vida, como seres vivos ou sistemas vivos. A esse respeito, Rodríguez e Torres (2003, p. 112-113) explicam:

A noção de autopoiésis serve para descrever um fenômeno radicalmente circular: as moléculas orgânicas formam redes de circulações que produzem [elas próprias] as mesmas moléculas as quais estão interligadas. Tais redes e interaçôes moleculares que produzem a si mesmas e especificam seus próprios limites são os seres vivos. Os seres vivos ficam então definidos como aqueles cujas características sáo as de produzirem a si mesmos; e ao indicar a organização que os define, chamamos de autopoiética.

Maturana e Varela são muito claros, quando empregam a seguinte metáfora, para explicar o conceito de autopoiésis: "A característica mais marcante de um sistema autopoiético é que ele se levanta por seus cordóes, e se constitui como distinto do meio circundante mediante sua própria dinâmica, de modo que ambas as coisas são inseparáveis." (MATURANA; VARELA, 1995, p. 87, grifos nossos). Os autores, em outros termos, conceituam a própria noção de emergência. Afirmam ainda que a organização do vivo, isto é, de todo o organismo vivo,

${ }^{20}$ O termo deriva do verbo grego poiéo, que significa fabricar (obras manuais), compor (obras intelectuais), construir (no trabalho agrícola). Aristóteles explicita o sentido principal da poiésis como uma prática na qual o agente e o resultado da ação estão separados ou são de natureza diferente. A poiésis liga-se à ideia de trabalho como fabricaçáo, construção, e à ideia de téchne. Esse termo foi proposto por Humberto Maturana e Francisco Varela. A história de sua concepção, como conceito e como neologismo, encontra-se contada pelos próprios autores, em Maturana e Varela (1980, 1995a, 1995b, 1997). Os autores conservaram, em espanhol, os dois termos gregos: autopoiesis; em inglês, também autopoiesis; em português, encontram-se grafadas de duas maneiras: autopoiese e autopoiésis; optou-se pela segunda.

${ }^{21}$ É importante salientar que citamos o trecho da introdução que Maturana fez, sem a participação de Varela, em Maturana e Varela (1980, p. 12). 
[...] é fundamentalmente um mecanismo de constituição de sua identidade como identidade material [...] toda interação da identidade autopoiética ocorre, não apenas em termos de sua estrutura físico-química, mas também como unidade organizada, isto é, em referência a sua unidade autoproduzida. (MATURANA; VARELA, 1980, p. 45-46, grifos dos autores).

Em outros termos, autopoiésis refere-se à propriedade que todo o sistema vivo tem de, a partir de seus próprios elementos, produzir a si próprio como unidade diferenciada em relação ao meio circundante ou ao entorno. Esse processo de autoprodução permite que tais sistemas vivos se autorreparem, se autorreestruturem, se autotransformem, se autoadaptem, sem que percam suas identidades. É isso o que os caracteriza e os define como sistemas vivos autopoiéticos (RODRIGUES; NEVES, 2017a).

Maturana defende também que os sistemas vivos existem em dois domínios operacionais. O primeiro domínio, por ele apontado, diz respeito à sua corporificação, ou seja, o domínio de sua própria composição como "vivo", ou como unidade discreta, "que é onde sua autopoiésis existe e de fato opera como uma rede fechada de produçóes moleculares." Isso significa dizer que se constitui em uma rede que se "dobra" sobre si mesma, formando uma unidade sistêmica, ou uma unidade autopoiética. O segundo domínio é o meio no qual tais sistemas vivos surgem, emergem, diferenciando-se, existindo como totalidades. "O primeiro é o domínio no qual o observador os vê em sua anatomia e fisiologia, e o segundo é onde o observador os distingue como organismos ou sistemas vivos." (MATURANA, 2001, p. 175).

As características acima descritas de um sistema autopoiético, quando consideradas, levam a importantes implicaçóes gnosiológicas e epistemológicas com relação ao pensamento sistêmico tradicional. Uma delas, por exemplo, é o fim do "dogma” teleológico. A noção de função, no funcionalismo tradicional, traz implícita a noção de um telós (finalidade), posto que, na epistemologia positivista-funcionalista, alguma coisa sempre está em função de alguma outra coisa, isto é, seu sentido (para o observador) se dá de modo relacional. Maturana e Varela ressaltam que "a espontaneidade no surgimento dos sistemas nega qualquer dimensão de intencionalidade ou finalidade [teleologia] em sua constituição ou em seu operar, e fazem com que a finalidade e a intencionalidade pertençam ao âmbito reflexivo do observador como comentários." (MATURANA; VARELA, 1995, p. 29). Os autores 
remetem toda a possibilidade de numa intencionalidade, de uma teleologia, à cognição do observador, ou seja, quem percebe (constrói) nexos lógicos finalistas (ou funcionalistas) é aquele que observa. Se for possível falar em "finalidade" de um sistema autopoiético, ela seria sempre uma autofinalidade (ser-em-si), quer dizer, a finalidade de manter a si como um existente (RODRIGUES, 2012; RODRIGUES; NEVES, 2017a).

O sociólogo alemão Niklas Luhmann, a partir da década de 1980, incorpora a noção de autopoiésis às suas pesquisas, que já vinham sendo desenvolvidas no campo da teoria sociológica sistêmica, há mais de vinte anos. Luhmann $(1998,2007)$ levanta um argumento teórico que chamou a atenção de inúmeros pesquisadores, no âmbito das ciências sociais, no mundo inteiro. Apontou para o fato de que, além dos organismos vivos, como sistemas autopoiéticos, nos moldes propostos por Maturana e Varela, existem outras classes de sistemas as quais se comportam dentro do mesmo padrão descrito pelos proponentes da autopoiésis. Boa parte do mérito e do reconhecimento de Luhmann se deve ao fato de ter demonstrado que sistemas, tais como o sistema psíquico e o sistema social (e seus subsistemas), apresentam comportamento idêntico aos sistemas orgânicos, quanto à explicação autopoiética, e, em função de tal argumento, propor uma potente e complexa teoria da sociedade.

Luhmann preconiza uma perspectiva teórica da sociedade, destacando a necessidade de se afrontar a crescente complexidade que o sistema social tem apresentado, como sociedade que se globaliza. Assim, destaca a necessidade de se rever e de se ultrapassar alguns "obstáculos epistemológicos" que têm pautado a maior parte dos esforços teóricos para o conhecimento da sociedade. Na perspectiva luhmanniana, a sociedade se constitui num sistema complexo, autorreferenciando-se, auto-organizando-se e autoproduzindo-se (autopoiésis), do ponto de vista de seu operar, expandindo-se (como não poderia ser diferente) em direção ao seu próprio interior, num processo continuamente inflacionário de aumento de complexidade (RODRIGUES; NEVES, 2017a).

A sociedade, assim, advém como resultado da sua própria complexidade, da sua necessária diferenciação (autodiferenciação) em subsistemas funcionais, que se auto-organizam (coabitando) a mesma unidade. A isso Luhmann chamou de coevolução sistêmica. Essa complexa inflação evolutiva constituída na própria noção de coevolução autopoiética opera inexoravelmente na diferenciação entre sistema/entorno, processo este inextrincável do conceito de autopoiésis, o qual, simultaneamente, ao permitir a emergência do sistema, reduz a complexidade do entorno. A teoria luhmanniana pressupóe importante 
nível de abstração, uma vez que, ao adotar o conceito de autopoiésis, transforma a sociedade em um sistema "vivo" que se automantém, se autorregula e se auto-observa, tendo como substrato a comunicação (RODRIGUES; NEVES, 2017a).

Nesse sentido, Luhmann esclarece que o que faz, do ponto de vista epistemológico, não é mera analogia. Para ele, ao descrever a sociedade como um sistema autopoiético, estabelece uma homologia entre esses dois domínios, pois identifica um mesmo comportamento entre os diferentes sistemas apontados. Enfatiza: "Meus argumentos não partem da analogia do ente, já que com respeito à teoria do conhecimento sigo o construtivismo. Penso que existem estruturas típicas muito gerais [sistemas como ordem] que permitem estabelecer comparaçôes, ou que possibilitam também um completo intercâmbio científico." (1992, p. 142-143).

\section{CONSIDERAÇÓEs FinaIS}

O presente artigo buscou problematizar e, talvez, contribuir, considerando o atual desenvolvimento da ciência e o debate que se tem travado, no âmbito do construtivismo científico, com a retomada reflexiva de alguns conceitos, tais como teoria, analogia, modelos e metáforas.

Tendo em vista certa crise da epistemologia (e também filosófica) de orientação analítica, para lidar com os próprios produtos que têm emergido da ciência, nesta contemporaneidade, em diferentes disciplinas do conhecimento científico, o artigo esforça-se por reanimar antigos debates, menos de caráter filosófico stricto sensu, mas mais de caráter epistemológico, com a reflexão teoria e o emprego de analogia em uma ciência que se mostra cada vez mais supradisciplinar e transparadigmática.

Por certo, como pano de fundo do argumento que se desenvolveu, ao longo do artigo, mas que não se tem condiçóes de ser explicitado aqui, de forma mais demorada, têm-se, por um lado, elementos de uma epistemologia de orientação histórica, a partir da segunda metade do século XX, da filosofia continental (BADIOU, 2013) e a sua influência na sociologia da ciência contemporânea, e, por outro lado, a possível confluência, mais de fundo, tanto no âmbito da filosofia como da ciência, das "crises" da filosofia analítica, da metafísica tradicional e do determinismo científico. Essa confluência de crises, que vem se apresentando como mais ou menos vigor aqui e ali, tem 
atravessado mais de um século e muito provavelmente tenha contribuído para, no âmbito da Ciência, sobre as questôes de contingência, precariedade, pósfundacionista e complexidade.

RODRIGUES, L. P. Post-deterministic, supradisciplinary and transparent-science science: rekindling the debate on theory, analogy and concept Trans/formlação, Marília, v. 43, n. 1, p. 151-172, Jan./Mar., 2020.

\begin{abstract}
AвSTRACT: This paper begins by discussing a classical theme in epistemology, namely analogy, concept, and theory using. It explores a contemporary perspective on scientific practies, Including some aspects of philosophical thinking. So it seeks to rekindle the always necessary debate on theory, analogy and concept about scientific production based on supradisciplinary and transparadigmatic approaches. In order to do so, we draw from different areas of scientific knowledge, classical and contemporary sociology, elements of biology, aspects of cybernetics, in order to demonstrate that science, considering its multiple disciplines, increasingly exchanges analogical reasoning. This is done to account for the growing complexity of current scientific knowledge.
\end{abstract}

KEYWORDS: Social sciences. Natural sciences. Theory and concept. Analogy and complexity.

\title{
REFERÊNCIAS
}

ASHBY, W. Ross. Introdução à cibernética. São Paulo: Perspectiva, 1970.

BADIOU, Alain. La aventura de la filosofia francesa a partir de 1960. Buenos Aires: Eterna Cadência, 2013.

BAUMER, Franklin. O pensamento europeu moderno: século XIX e XX. v. II, Lisboa: Ediçôes 70, 1977.

BOURDIEU, Pierre; CHAMBOREDON, Jean-Claude; PASSERON, Jean-Claude. $A$ profissão de sociólogo. Petrópolis: Vozes, 1999.

BUCKLEY, Walter (ed.). Modern systems research for the behavioral scientist. Chicago: Aldine, 1969.

CAPRA, Fritjof. A Teia da Vida. São Paulo: Cultrix, 1997.

CLAM, Jean. Questóes fundamentais de uma teoria da sociedade: contingência, paradoxo, só-efetuação. São Leopoldo: Editora Unisinos, 2006.

COMTE, Auguste. Curso de Filosofia Positiva. São Paulo: Abril Cultural, 1983 (Coleção

Os Pensadores). 
DELEUZE, Gilles; GUATTARI, Félix. O que é filosofia? Rio de Janeiro: Editora 34, 1992. DUPUY, M. Jean-Pierre. Nas origens das ciências cognitivas. São Paulo: UNESP, 1996. DURKHEIM, Emile. Vida e Obra. São Paulo: Abril Cultural, 1978 (Coleção Os Pensadores).

DURKHEIM, Emile. Da divisão do trabalho social. São Paulo: Martins Fontes, 1995.

EPSTEIN, Isaac. Introdução. In: EPSTEIN, Isaac. Cibernética e comunicação. São Paulo: Cultrix, 1973.

FOERSTER, Heinz von. Undertanding undertanding. Essay on Cybernetics and Cognition. New York: Springer, 2003.

FOERSTER, Heinz von. Las semillas de la cibernética. Barcelona: Gedisa, 2006.

HESSE, Mary B. Models and analogies in science. Notre Dame: University of Notredame Press, 1966.

LUHMANN, Niklas. Estudos Sociológicos. México: El Colegio de México, v. X, 1992. p. 137-150.

LUHMANN, Niklas. Sistemas Sociales: Lineamentos para una teoría general. Rudí (Barcelona): Anthropos; México Universidad Iberoamericana: Santa Fé de Bogotá: CEJA, Pontificia Universidad Javeriana, 1998.

LUHMANN, Niklas. La sociedad de la sociedad. México: Iberoamericana/Herder, 2007.

MATURANA, Humberto. Cognição, ciência e vida cotidiana. Belo Horizonte: Editora UFMG, 2001.

MATURANA, Humberto; VARELA, Francisco. Autoposieis and cognition: The Realization of the Living. London: D. Reidel, 1980.

MATURANA, Humberto; VARELA, Francisco. A Árvore do conhecimento: as bases biológicas do entendimento humano. Campinas: Posy II, 1995a.

MATURANA, Humberto; VARELA, Francisco. De Máquinas y Seres Vivos - Autopoiesis: la organización de lo vivente. Santiago do Chile: Universitária, 1995b.

MCCULLOCH, Warren; PITTS, Walter. A Logical Calculus of the Ideas Immanent in Nervous Activity. Bulletin of mathematical of biophysics. Chicago, v. 5 p. 115-133, 1943.

MENDONÇA, Daniel; RODRIGUES, Léo Peixoto. Laclau e Luhmann: um diálogo possível. In: RODRIGUES, L. Peixoto; MENDONÇA, Daniel. Ernesto Laclau e Niklas Luhmann: Pós-fundacionismo, abordagem sistêmica e as organizaçóes sociais. Porto Alegre: EDIPUCRS, 2006, p. 87-99.

MOYA, Carlos. La division del trabajo social em Emile Durkheim. Revista do Trabajo, Madrid, n. 30, p. 87-98, 1972.

PRIGOGINE, Ilya. O fim das certezas. São Paulo: UNESP, 1996. 
RODRIGUES, Léo Peixoto. Analogias, Modelos e Metáforas na Produção de Conhecimento em Ciências Sociais. Pensamento Plural, v. 1, p. 11-28, 2007.

RODRIGUES, Léo Peixoto. O Estruturalismo Francês: aspectos históricos e epistemológicos. In: SCHULZ, Rosangela (org.). Ensaios de Sociologia e Politica. Pelotas: UFPel, 2010.

RODRIGUES, Léo Peixoto. Da fisiologia à Sociologia? Elementos para uma revisão da história teórica da sociologia sistêmica. Revista Brasileira de Ciências Sociais, v. 28, n. 82, p 165-178, jun. 2013.

RODRIGUES, Léo Peixoto; NEVES, Fabrício. A Sociologia de Niklas Luhmann. Petrópolis-RJ: Vozes, 2017a.

RODRIGUES, Léo Peixoto; NEVES, Fabrício (org.). Sistemas sociais: ensaios teóricos. Porto Alegre: EDIPUCRS, 2017b.

RODRÍGUEZ, Darío R.; TORRES, Javier N. Autopoiesis, la unidad de una diferencia: Luhmann y Maturana. Sociologias. Porto Alegre: UFRGS. n. 9, p. 106-140, jan./jun. 2003.

SPENCER, Herbert. Primeiros principios. Biblioteca Universal Virtual, 2003. Disponível em: http://www.alejandriadigital.com/wp- content/uploads/2016/01/SPENCER, $\% 20$ Herbert\%20-\%20Primeros\%20Principios.pdf Acesso em: 18 nov. 2016.

WIENER, Norbert; SCHADÉ, Joahnnes. P. (ed.). Cybernetics of the nervous systems. New York: Elsevier, 1965. 